\title{
Internalismo moral y justicia global ${ }^{1}$ Moral Internalism and Global Justice
}

\author{
LUCIANO VENEZIA \\ Universidad Nacional de Quilmes, Argentina
}

\begin{abstract}
RESUMEN. En este trabajo caracterizo y evalúo un argumento que David Miller formula contra la concepción cosmopolita de la justicia internacional. Miller afirma que la justicia cosmopolita es excesivamente demandante y consiguientemente sólo puede ser cumplida por «héroes» pero no por personas regulares. Sobre la base de estas consideraciones, Miller asegura que los principios de justicia distributiva sólo pueden tener un ámbito de aplicación nacional y que no pueden extenderse a uno global. Por mi parte, entiendo que las consideraciones psicológico-morales desarrolladas por Miller son insuficientes para abandonar al cosmopolitismo y justificar la adopción de la posición nacionalista liberal.
\end{abstract}

Palabras clave: nacionalismo, cosmopolitismo, justicia internacional, internalismo moral, David Miller.
ABSTRACT. In this paper I characterize and evaluate an argument David Miller develops against cosmopolitan conceptions of international justice. Miller argues that cosmopolitan justice is too demanding and so it can be discharged only by «heroes» but not by regular people. On this basis, Miller alleges that principles of distributive justice can only have a domestic scope and cannot be extended to encompass the globe. I argue that the psychological considerations developed by Miller are insufficient to warrant the abandoning of cosmopolitanism and justify the adoption of liberal nationalism.

Key words: nationalism, cosmopolitanism, international justice, moral internalism, David Miller.

\section{Introducción}

La disputa entre concepciones de la justicia nacionalistas y cosmopolitas constituye un hito en el debate contemporáneo sobre justicia distributiva in-

1 Una versión resumida de este trabajo titulada «Psicología moral y justicia internacional: la crítica nacionalista al cosmopolitismo» fue presentada en las VII Jornadas de Investigación en Filosofía organizadas por el Departamento de Filosofía, Facultad de Humanidades y Ciencias de la Educación, Universidad Nacional de La Plata (Argentina) y será publicada en las actas de dicho evento. Agradezco especialmente a José Fernández Vega y Graciela Vidiella por sus comentarios. Asimismo, agradezco los comentarios y sugerencias de Facundo García Valverde, Martín Hevia y Uwe Steinhoff a una versión anterior de este trabajo. 
ternacional. En este trabajo caracterizo y evalúo críticamente uno ${ }^{2}$ de los argumentos que David Miller formula contra la posición cosmopolita.

Miller adopta como punto de partida una concepción internalista de la motivación moral. Sobre esa base, arguye que si bien individuos regulares se verían normalmente motivados a cumplir con principios de justicia a nivel nacional, no lo estarían en el caso de que esos principios se extendieran por fuera de las fronteras nacionales y alcanzaran un ámbito global. En este caso, sólo cumplirían con las demandas de justicia personas especialmente motivadas - «héroes». Sobre la base de las consideraciones psicológico-morales recién mencionadas, Miller sostiene que deberíamos rechazar la tesis cosmopolita de que las consideraciones de justicia distributiva tienen un alcance global. A su juicio, en cambio, los principios de justicia distributiva tendrían un ámbito de aplicación restringido, limitado por las fronteras de los diferentes Estado-nación. De esta forma, Miller adopta una concepción que entiende que

[...] la búsqueda de la justicia involucra una división del trabajo entre las esferas domésticas e internacionales, en donde los Estados [nacionales] tienen la responsabilidad primaria de promover la justicia social entre sus ciudadanos, mientras que la principal tarea de la comunidad internacional es crear las condiciones bajo las cuales esa responsabilidad pueda ser cumplida. En algunas circunstancias, ello requerirá intervención, cuando los Estados no puedan o no quieran proveer niveles mínimos de derechos y recursos a sus ciudadanos. Pero [esta concepción] no cuestiona de un modo fundamental la idea de autonomía [nacional] y no busca alcanzar la uniformidad global en el sentido de que las personas de cualquier lugar [del planeta] disfruten del mismo paquete de derechos, recursos y oportunidades ${ }^{3}$.

Por mi parte, entiendo que las consideraciones que este autor avanza son menos destructivas de lo que él considera. La argumentación milleriana no permite considerar que el cosmopolitismo sea una concepción de la justicia distributiva que requiera de las personas más de lo que razonablemente podemos esperar que ellas hagan. En todo caso, en este respecto, la posición cosmopolita se encuentra con dificultades similares a las que se presentan al interior de las comunidades nacionales. Consiguientemente, todo parece indicar que no existen las dificultades específicas o características de la aplicación de principios de justicia al ámbito global que, según Miller, serían fatales para la

2 Éste no es el único argumento anti-cosmopolita desarrollado por Miller. Cf. D. Miller, On Nationality, Oxford, Clarendon Press, 1995, cap. 3. Razones de espacio no me permiten considerar las restantes consideraciones millerianas.

3 D. Miller, National Responsibility and Global Justice, Oxford, Oxford University Press, 2007 , p. 21. Miller caracteriza a esta posición como «liberalismo social» basándose en C. Beitz, «International Liberalism and Distributive Justice: A Survey of Recent Thought», World Politics, Vol. 51, No. 2 (1999), pp. 269-296. Por mi parte, en este trabajo me voy a referir a la posición de Miller como «nacionalista». 
articulación de una posición cosmopolita. Por ello, mi conclusión será que las consideraciones introducidas por Miller no ofrecen mayores razones para abandonar al cosmopolitismo y adoptar al nacionalismo en cuestiones de justicia distributiva internacional.

El presente trabajo está estructurado de la siguiente forma. En la sección 2 caracterizo a las concepciones nacionalista y cosmopolita de la justicia internacional. En la sección 3 desarrollo las consideraciones basadas en la teoría internalista de psicología moral introducidas por Miller para justificar su rechazo del cosmopolitismo. En la sección 4 evalúo críticamente ese argumento. A mi juicio, las consideraciones psicológico-morales introducidas por Miller son insuficientes para considerar que el cosmopolitismo sea una concepción de la justicia distributiva errada o irrazonable. Finalmente, en la sección 5 presento mis conclusiones.

\section{Nacionalismo y cosmopolitismo}

Conviene comenzar caracterizando a las dos concepciones de la justicia distributiva en disputa. Tomando la formulación de Thomas W. Pogge, el cosmopolitismo ${ }^{4}$ involucra tres tesis particulares: (1) individualismo: las unidades últimas de atención moral son las personas individuales; (2) universalidad: el estatus de unidad última de atención moral se predica igualmente de todas las personas; (3) generalidad: todas las personas deben igual atención moral a todas las restantes personas ${ }^{5}$. Sobre la base de la articulación de estas tesis, el cosmopolitismo requiere que los esquemas distributivos a nivel internacional sean considerados de forma independiente de las características particulares de los individuos, incluyendo su pertenencia a una comunidad política particular. Desde la perspectiva cosmopolita, la nacionalidad no tiene mayor peso normativo. A contrario sensu, el nacionalismo liberal ${ }^{6}$ arguye

4 En el presente trabajo uso «cosmopolitismo» para referirme al cosmopolitismo moral. El cosmopolitismo moral es conceptualmente independiente del cosmopolitismo político, que evalúa consideraciones acerca de la deseabilidad de la existencia de instituciones políticas (incluyendo un gobierno planetario) que vayan más allá de las propias de los Estado-nación. Sin embargo, Miller considera que estas dos concepciones del cosmopolitismo no pueden separarse fácilmente. Cf. D. Miller, «Cosmopolitanism: A Critique», Critical Review of International Social and Political Philosophy, Vol. 5, No. 3 (2002), p. 84 y Miller, National Responsibility..., cit., pp. 24-27. En este trabajo, dejo de lado esta complicación.

5 T. Pogge, «Cosmopolitanism and Sovereignty», Ethics, Vol. 103, No. 1 (1992), pp. 48-49. Mi caracterización de las tres tesis se basa en P. Gilabert, «Comentarios sobre la concepción de la justicia global de Pogge», Revista Latinoamericana de Filosofía, Vol. XXXIII, No. 2 (2007), p. 207.

${ }^{6}$ Por supuesto, el nacionalismo puede no ser entendido en términos liberales. De todos modos, el nacionalismo liberal es la concepción de mayor relevancia en el debate contemporáneo sobre justicia distributiva a nivel internacional. Los nacionalistas liberales entienden que la 
que la pertenencia a una determinada nación constituye una fuente clave de relaciones asociativas, que los miembros de tales comunidades ${ }^{7}$ políticas valoran especialmente. Los nacionalistas consideran que este elemento tiene un carácter normativo fundamental que, entre otras cosas, implica que consideraciones de justicia distributiva tienen primordialmente lugar dentro de las fronteras de los diferentes Estado-nación. De esta forma, a juicio de los nacionalistas, el locus privilegiado de la justicia distributiva está circunscripto por los límites de las diferentes comunidades nacionales, lo que implica una posición contraria a la tesis cosmopolita de que existen principios de justicia más o menos igualitarios de alcance global ${ }^{8}$.

pertenencia a una nación no debe ser el privilegio de un grupo particular de individuos sino de todas las personas que pueblan el planeta y, por tanto, consideran que el bien de pertenecer a una nación es algo que debe ser reconocido para todos. Consiguientemente, típicamente entienden que las diferentes naciones poseen un derecho a la auto-determinación. Cf. e.g. Miller, On Nationality, cit., cap. 4. En el caso de Miller, él entiende que la auto-determinación nacional está fundada en el valor cuasi-evidente de la autonomía (personal y de grupo). Cf. D. Miller, «National Self-Determination and Global Justice», en su Citizenship and National Identity, Cambridge, Polity Press, 2000, pp. 164-166. Sin embargo, los nacionalistas no consideran necesario que las comunidades nacionales se organicen políticamente como Estados, aunque Miller considera que ello es deseable, en tanto «un Estado independiente es posiblemente el mejor medio del que dispone una nación para satisfacer su derecho a la auto-determinación». Miller, On Nationality, cit., p. 81. (En el caso de la existencia de comunidades multi-nacionales, algunos nacionalistas argumentan que deberían organizarse políticamente como federaciones multi-nacionales. Cf. e.g. Y. Tamir, Liberal Nationalism, Princeton, Princeton University Press, 1992, p. 9. Por su parte, además de esta opción, Miller considera la posibilidad del rediseño de las fronteras junto con la promoción de migración voluntaria, así como la creación de una nueva identidad nacional que incorpore a los diferentes grupos nacionales. Cf. D. Miller, «Nationality: Some Replies», Journal of Applied Philosophy, Vol. 14, No. 1 (1997), p. 80.

7 Los nacionalistas conceptualizan a la nación en términos comunitaristas. Por ejemplo, Miller entiende que la nación es una entidad sui generis en la cual las personas comparten cosas tales como una historia común, una cultura distintiva, un territorio específico y una cultura pública distintiva. Cf. Miller, On Nationality, cit., pp. 21-27. La crítica que seguramente podríamos realizar en este punto es que la caracterización de las sociedades democrático-constitucionales modernas como comunidades es empíricamente errada y que, en cambio, ellas se caracterizan por la existencia de un profundo pluralismo filosófico, religioso y moral. Adicionalmente, podría argüirse que ese pluralismo es razonable, i.e. que es el resultado del ejercicio de la razón teórica y práctica en un contexto medianamente libre de dogmatismos antes que de la irracionalidad de los ciudadanos. Por supuesto, esta es la apreciación de John Rawls. Cf. J. Rawls, Political Liberalism, edición en rústica, Nueva York, Columbia University Press, 1996, pp. 36-37. De todos modos, en este trabajo dejo de lado estas importantes dificultades.

8 Strictu sensu no es cierto que Miller crea que los deberes de justicia sólo existen entre los miembros de la misma nación. Cf. Christian Barry y Pablo Gilabert, «Does global egalitarianism provide an impractical and unattractive ideal of justice?», International Affairs, Vol. 84, No. 5 (2008), p. 1027. Miller considera que existen principios de justicia internacional que conforman la posición que llama «cosmopolitismo débil». Sin embargo, a mi juicio, el cosmopolitismo débil no constituye una genuina concepción de la justicia distributiva global sino que, más bien, ella da cuenta de una cierta concepción de los deberes morales de humanidad. Cf. infra, sección 4. 
Ciertamente, creencias normativas de corte nacionalista son frecuentes entre los miembros de las distintas comunidades nacionales. Las personas comúnmente tienen lazos específicos para con sus compatriotas ${ }^{9} \mathrm{y}$ típicamente consideran que tales nexos generan deberes especiales para con ellos. Así, muchos creen que tienen obligaciones morales para con los restantes miembros de su comunidad nacional que no tienen para con el resto de la humanidad y entienden que esas obligaciones tienen prioridad por sobre el resto de los deberes morales que sí tienen para con los miembros de otras comunidades políticas, incluso en aquellos casos en los que los últimos se encuentren en situaciones más desventajosas que los primeros ${ }^{10}$. Los nacionalistas estiman que estas consideraciones tienen una importancia normativa fundamental y, sobre esta base, cuestionan la justificación de las concepciones cosmopolitas de la justicia internacional ${ }^{11}$. Pero aquí no termina la cuestión. Los propios defensores de posiciones cosmopolitas entienden que una concepción de la justicia distributiva global atendible debe considerar seriamente elementos como aquellos a los que apelan los nacionalistas para argumentar en contra de su propia posición. Por ejemplo, Charles R. Beitz escribe en este sentido que «la debilidad filosófica más característica de las teorías cosmopolitas [...] reside en el fracaso de no tomar de forma suficientemente seria a las relaciones asociativas que los individuos desarrollan y ciertamente deben desa-

9 Los nacionalistas típicamente se refieren a los miembros de la misma comunidad política como «compatriotas». Sin embargo, ello no está exento de dificultades. Daniel Weinstock dice que «por medio de «compatriota» podemos querer decir tres cosas: podemos querer decir concitoyen, esto es, ciudadano del mismo Estado; co-nacional, esto es, miembro de la misma nación; o co-residente, esto es, una persona que reside, en el sentido legal completo [del término] en el mismo territorio que yo. [Ahora bien,] [a] unque estos conceptos puedan coincidir extensionalmente en grado suficiente, ellos son intensionalmente completamente diferentes. Residencia y ciudadanía son nociones legales que denotan diferentes niveles de vínculo legal con un Estado, mientras que la nacionalidad denota la pertenencia a una comunidad histórica que puede o no coincidir con las fronteras del Estado». D. Weinstock, «National Partiality: Confronting the Intuitions», Monist, Vol. 82, No. 3 (1999), pp. 534-535. A mi juicio, el uso del término «compatriota» está relacionado al comunitarismo típico de los nacionalistas. De cualquier modo, un análisis detallado de este punto está por fuera de los objetivos del presente trabajo.

10 Por supuesto, ello no significa que tengan prioridad sobre cualesquiera deberes morales. Ciertamente, los nacionalistas liberales no creen que el (supuesto) deber de proveer a los propios compatriotas con una distribución más o menos igualitaria de bienes tiene prioridad sobre los deberes de matar o robar a los extranjeros.

11 En este trabajo no evalúo las diferencias de contenido de las diferentes concepciones cosmopolitas y, en cambio, las considero como formando parte de un conjunto más o menos homogéneo de concepciones de la justicia. Sin embargo, es claro que ello no es más que una simplificación. Así como existen diferentes concepciones liberal-igualitarias dentro del campo de las concepciones de la justicia distributiva de nivel nacional (e.g. el igualitarismo estricto de bienestar, recursos o capacidades, diferentes concepciones más o menos exigentes de la igualdad de oportunidades, el principio de la diferencia, etc.) esas mismas concepciones (y otras) pueden extenderse para el caso de la justicia internacional. En ese caso, seguramente todas ellas conformarían concepciones de la justicia de corte cosmopolita. 
rrollar para vivir vidas exitosas y gratificantes» ${ }^{12}$. De esta forma, la crítica nacionalista al cosmopolitismo tiene una importancia capital para los que defienden este tipo de concepción de la justicia global. Los nacionalistas enfatizan precisamente las relaciones asociativas que, en el marco de una nación, los individuos desarrollan con sus compatriotas y que generan obligaciones especiales para con ellos. Por tanto, la consideración de la perspectiva nacionalista constituye una tarea imprescindible para justificar la racionalidad de la posición cosmopolita de la justicia internacional ${ }^{13}$.

La incompatibilidad del nacionalismo con el cosmopolitismo en cuestiones de justicia distributiva internacional es directa. El individualismo normativo del que parte la posición cosmopolita conlleva el diseño de principios normativos de alcance global que aseguren un trato imparcial a las personas que podrían ser afectadas por ellos ${ }^{14}$. La nacionalidad, del mismo modo que

12 Beitz, op. cit., p. 291.

13 Seguramente podría argüirse que la tesis de que la nación es el marco privilegiado de asociación entre las personas es empíricamente dudosa y, como mucho, anacrónica. Efectivamente, en el marco del mundo moderno, las vidas de las personas en casi cualquier espacio del globo se ven profundamente influidas por actividades que individuos, corporaciones multinacionales, agencias internacionales, organizaciones no-gubernamentales, etc. realizan en otros lugares del planeta. Por tanto, las relaciones que caracterizan al mundo moderno no son meramente nacionales sino, también, internacionales. Ello parece erosionar la noción misma de soberanía nacional y, en cualquier caso, parece minar la tesis de que las relaciones internaciones se dan únicamente entre Estados. Sin embargo, los nacionalistas podrían argüir que la relevancia de estas consideraciones respecto del punto en cuestión es limitada. Efectivamente, ellos no cuestionan apreciaciones de tipo empírico acerca de la forma en que los individuos se relaciones entre sí. El punto clave radica en la forma en que los ciudadanos de las diferentes comunidades nacionales visualizan los vínculos específicos que desarrollan. En particular, los nacionalistas enfatizan que las personas creen que los nexos que las personas tienen para con sus compatriotas generan deberes de un tipo especial (por ejemplo, deberes fundados en consideraciones de justicia) que ellos no consideran que tengan para con los habitantes de otras comunidades nacionales. Por tanto, según los nacionalistas, el hecho de que existan relaciones entre los individuos a nivel internacional es normativamente irrelevante, en la medida en que los propios individuos minimizan la existencia de tales relaciones o entienden que ellas no tienen consecuencias importantes. Por mi parte, estimo que la justificabilidad de este tipo de apreciaciones es discutible. El punto en cuestión no consiste meramente en acomodar los sentimientos o actitudes afirmados efectivamente por las personas; también debe evaluarse su razonabilidad. Igualmente, a los efectos del presente trabajo, asumo que las consideraciones enfatizadas por los nacionalistas son atendibles. Cf. de todos modos D. Jones, «Revenge of the Philosophical Mole: Another Response to David Miller on Nationality», Journal of Applied Philosophy, Vol. 13, No. 1 (1996), esp. pp. 76-77 para una crítica en esta línea a la posición de Miller.

$14 \mathrm{Sin}$ embargo, ello no implica que los diferentes actores políticos (fundamentalmente, los Estados nacionales) deban tratar a todos los individuos de manera imparcial. Un cosmopolita como Pogge, por caso, asegura que «[p]or cierto no se espera que un gobierno [nacional] atribuya el mismo peso a los intereses de todos los seres humanos del mundo. Antes bien, se le concede cierta parcialidad en la manifestación de una preocupación especial por los intereses de su propia gente, actual y futura». De todos modos, a juicio de Pogge, «existen limitaciones éticas evidentes en la parcialidad de los gobiernos [...] En términos bastante generales, la parcialidad es legítima solamente dentro del contexto de un «campo de juego parejo», concebido en sentido amplio, que incluye normas justas administradas de forma imparcial». T. Pogge, 
los resultados de la lotería natural y social, es considerada por los cosmopolitas, adoptando la terminología que John Rawls utiliza en otro contexto, como un elemento «arbitrario desde un punto de vista moral» ${ }^{15}$.

Los nacionalistas están en desacuerdo. Ellos consideran que el hecho de que los miembros de las comunidades nacionales entiendan que sus compatriotas tienen prioridad sobre los demás habitantes del globo establece una profunda diferencia entre la nacionalidad y otras características contingentes de las personas. Sobre esa base, los nacionalistas entienden que los miembros de las diferentes comunidades políticas deben recibir una consideración o trato especiales por parte de sus conciudadanos. Miller escribe en este sentido que «las naciones son comunidades éticas». Por tanto, considera que «cuando reconozco mi identidad nacional también reconozco que tengo obligaciones especiales para con los miembros de mi nación que no tengo para con otros seres humanos» ${ }^{16}$. En el mismo sentido, Miller escribe que «las naciones son comunidades de obligación, en el sentido de que sus miembros reconocen el deber de satisfacer las necesidades básicas y proteger los intereses básicos de los otros miembros [de la comunidad nacional]» ${ }^{17}$. Kok-Chor Tan explica que, a juicio de los nacionalistas, la nacionalidad provee del elemento crucial «a través del cual individuos separados y no-relacionados en primer lugar pueden verse a sí mismos como mutualmente debidos y moralmente relacionados y, por tanto, proveyendo el fundamento y la motivación requeridas para que consideraciones de justicia social [puedan tener lugar] entre los ciudadanos» ${ }^{18}$.

De esta forma, los nacionalistas consideran que algunos individuos (los miembros de las diferentes comunidades políticas nacionales) poseen el dere-

«¿Qué es la justicia global?», Revista Latinoamericana de Filosofia, Vol. XXXIII, No. 2 (2007), p. 201.

15 Cf. J. Rawls, A Theory of Justice, edición revisada, Cambridge, The Belknap Press of Harvard University Press, 1999, p. 14. En este sentido, por ejemplo, Pogge escribe que «la nacionalidad es sólo otro profundo elemento contingente más (como la dotación genética, la raza, el género y la clase social), una base potencial más de desigualdades que son con inescapables y que están presentes desde el nacimiento». T. Pogge, Realizing Rawls, Ítaca, Cornell University Press, 1989, p. 247. Sin embargo, ello no significa que los grupos nacionales o de otro tipo no sean importantes desde un punto de vista cosmopolita. Pero ellos reciben una consideración diferente de la que le asignan los nacionalistas. Por ejemplo, a juicio de Robert Goodin, los lazos nacionales y, por tanto, las obligaciones especiales que ellos generan, tienen un fundamento instrumental: «las responsabilidades especiales son [...] asignadas meramente como un instrumento administrativo para [facilitar] el cumplimiento de nuestros deberes [universales] más eficientemente». R. Goodin, "What is So Special about Our Fellow Countrymen?», Ethics, Vol. 98, No. 4 (1988), p. 685, citado por Miller, On Nationality, cit., p. 62.

16 Miller, On Nationality, cit., p. 49. Cf. también ibíd., p. 11.

17 Ibid., p. 83. Miller defiende largamente esta concepción en National Responsibility..., cit., pp. 34-43.

18 Tan, K., «Liberal Nationalism and Cosmopolitan Justice», Ethical Theory and Moral Practice, Vol. 5, No. 4 (2002), p. 436. 
cho a un trato especial por parte de otros individuos (sus compatriotas) sólo por el hecho de que pertenecen a la misma nación ${ }^{19}$. Miller asegura en este sentido que él defiende «la visión de que las fronteras nacionales pueden ser éticamente significativas. Los deberes que tenemos para con nuestros compatriotas pueden ser más amplios que los deberes que tenemos para con los extranjeros, simplemente por el hecho de que ellos son nuestros compatriotas» ${ }^{20}$. Consiguientemente, los nacionalistas adoptan una perspectiva parcialista ${ }^{21}$ acerca de la cuestión de qué obligaciones morales los individuos tienen para con el resto de las demás personas. Por supuesto, estos elementos tienen consecuencias importantes al momento de considerar la existencia misma de deberes de justicia distributiva de alcance global. La justicia distributiva, a juicio de los nacionalistas, sólo puede tener lugar dentro de las fronteras nacionales. En palabras de Tan:

[e]l nacionalismo promueve, entre otras cosas, un sentido de consideración especial entre los miembros [de la misma comunidad nacional] o connacionales. Un nacionalismo que no promueva, por no decir que permita, patriotismo, lealtad y una consideración especial por nuestros connacionales sería una forma vacía de nacionalismo. El problema, algunos han argumentado, es que esta consideración especial para con los connacionales [...] contradice la imparcialidad de la justicia global ${ }^{22}$.

El cosmopolitismo y el nacionalismo constituyen posiciones normativas incompatibles ${ }^{23}$. ¿Qué concepción debemos favorecer? Prima facie, la res-

19 Tan señala que «[d]e acuerdo a nacionalistas como Miller, yo tengo una obligación para con mis compatriotas simplemente porque ellos son mis compatriotas. Ninguna justificación o explicación adicional es necesaria o disponible. La relación especial [que existe] entre compatriotas en sí misma provee de razones para la acción no-reducibles [a consideraciones más básicas]». K. Tan, «The demands of justice and national allegiances», en G. Brock y H. Bridhouse (eds.), The Political Philosophy of Cosmopolitanism, Cambridge, Cambridge University Press, pp. 174-175.

20 D. Miller, «The Ethical Significance of Nationality», Ethics, Vol. 98, No. 4 (1988), p. 647.

21 De todos modos, Miller cree que la terminología de «parcialidad» e «imparcialidad» es inadecuada. Cf. Miller, On Nationality, cit., pp. 53-55 y Miller, «Nationality: Some Replies», p. 76. Otro modo de caracterizar la diferencia entre nacionalismo y cosmopolitismo podría apelar a diferentes tipos de razones, en particular, razones relativas respecto de los agentes y razones neutrales respecto de los agentes. Los sentimientos de las personas para con sus compatriotas generarían razones relativas respecto de los agentes, aunque los nacionalistas pueden no necesariamente entenderlo de esa forma. Cf. Jones, op. cit., pp. 79-80.

22 Tan, «Liberal Nationalism...», cit., p. 454.

23 Esta conclusión no es compartida universalmente. Por ejemplo, Tan no cree que exista una genuina contraposición entre nacionalismo y cosmopolitismo. En cambio, él considera que la interpretación correcta de la concepción cosmopolita puede reconocer y acomodar sentimientos nacionalistas de corte liberal. Cf. ibíd., pp. 445-457 y K. Tan, Justice without Borders: Cosmopolitanism, Nationalism, and Patriotism, Cambridge, Cambridge University Press, 2004, caps. 5-6. En lo que a mi respecta, soy escéptico acerca de la plausibilidad de sus argumentos. De todos modos, la evaluación de esas consideraciones está por fuera de los alcances 
puesta parece depender de la forma en que ponderemos el valor de las relaciones asociativas que se generan en el interior de los diferentes Estado-nación que subrayan los nacionalistas vis-à-vis la forma en que entendamos la idea de una misma consideración imparcial hacia los reclamos de las personas en todo el planeta que enfatizan los cosmopolitas. Ahora bien, parecen existir buenas razones ${ }^{24}$ para valorar tanto la existencia de consideraciones especiales como para adoptar una perspectiva imparcial respecto de los reclamos de los individuos. Por un lado, parece cierto que nuestra vida moral se ve enriquecida por la existencia de obligaciones generadas por elementos particulares de nuestra relación con otras personas. La mayoría de las personas que reflexiona sobre esta cuestión parece reconocer la existencia de obligaciones especiales para con familiares, amigos, colegas, etc. y, como arguyen los nacionalistas, para con compatriotas; de ahí la dificultad filosófica señalada más arriba que enfrenta la concepción cosmopolita. Estas obligaciones no están fundadas en principios externos. Por tanto, la existencia de estos sentimientos y vínculos parecen constituir elementos claves que cualquier concepción de la justicia distributiva simpliciter y a fortiori de la justicia internacional medianamente atendible debería acomodar ${ }^{25}$. Sin embargo, por otro lado, los cosmopolitas parecen estar

planteados en el presente trabajo. En cambio, en este contexto asumo el punto de partida intuitivo de que el nacionalismo y el cosmopolitismo son normativamente incompatibles.

24 Una crítica al nacionalismo que Miller menciona y rechaza es la de conservadurismo moral. Pero Miller considera que esta acusación errada. En realidad, Miller cree que su concepción nacionalista no sólo no involucra un componente conservador sino que tiene un fuerte carácter crítico. Miller asegura que «en la medida en que las identidades nacionales y la cultura política que ayuda a componerla está formada por un proceso de reflexión racional en el cual los miembros de la comunidad pueden contribuir en pie de igualdad esta acusación [de conservadurismo moral] no se aplica más. Las obligaciones que ahora reconocemos no son meramente tradicionales, sino que cargan con la marca de las razones varias que han sido señaladas a lo largo del tiempo en el curso de estos debates». Miller, On Nationality, cit., p. 70. Por mi parte, no estoy convencido de que el componente crítico que Miller enfatiza forme una parte nuclear de esta concepción. En todo caso, ello parece un elemento contingente y, como tal, puede o no estar presente dependiendo del caso particular en cuestión. Cf. D. Weinstock, «Is there a Moral Case for Nationalism?», Journal of Applied Philosophy, Vol. 13, No. 1 (1996), pp. 90-91. Por supuesto, no creo que cualquier posición anti-cosmopolita esté fundada sobre, o al menos esté comprometida con, una posición excesivamente conservadora. La concepción de Miller en otras materias - fundamentalmente, en justicia distributiva a nivel nacional - no tiene esta característica y no parece obvio que ello involucre algún tipo de contradicción o constituya una posición moralmente esquizofrénica. Pero de ello no se sigue que la posición milleriana necesariamente tenga el carácter crítico que su autor le asigna.

25 En este sentido, Tan escribe que «[s]i la idea cosmopolita de la justicia va a tener algún efecto [práctico] en los seres humanos, debe reconocer los vínculos y compromisos locales que tienen las personas y que son característicos de la mayoría de las vidas humanas significativas y valiosas. Entre los lazos especiales y compromisos que las personas comparten están aquellos de la nacionalidad. De este modo, el desafío para los cosmopolitas es mostrar cómo ellos pueden acomodar y dar cuenta de los sentimientos nacionales sin comprometer su motivación y compromiso por la igualdad global. Una teoría de la justicia que no acomode y reconozca de forma apropiada los vínculos especiales y las obligaciones de la nacionalidad compartida no 
en lo correcto al llamar la atención sobre la idea de que todos los individuos del planeta son poseedores de un derecho a una igual consideración y respeto por parte de los demás habitantes del globo, independientemente de todo tipo de elementos contingentes, incluyendo su nacionalidad.

Ciertamente, debemos evaluar el debate entre nacionalistas y cosmopolitas desde una perspectiva aceptable para ambas partes. Ahora bien, como señalé recién, el caso parece ser tal que la posición que tomemos al respecto va a resultar incapaz de acomodar las intuiciones que fundamentan a la posición contraria. Por tanto, cualquier decisión que tomemos tiene fuertes chances de ser arbitraria. Así las cosas, la dicotomía parcialismo nacional vs. imparcialismo cosmopolita parece intratable: independientemente de qué posición adoptemos pareciera que necesariamente estaremos dejando de lado consideraciones normativas fundamentales. Con todo, este no es el final de la cuestión. Miller elabora una serie de consideraciones psicológico-morales para fundamentar la posición nacionalista que pareciera que los cosmopolitas deberían asimismo reconocer. Miller asegura que los principios de justicia cosmopolita sólo podrían ser cumplidos por «héroes» pero no por personas regulares. Ahora bien, una concepción de la justicia internacional incapaz de generar la adhesión de las personas difícilmente podría considerarse justificada. Sin embargo, ello no significa que la balanza se incline hacia el lado de aquellos - como los nacionalistas - que resisten la idea misma de justicia global. Por mi parte, estimo que los elementos de juicio introducidos por Miller son insuficientes para decidir la cuestión entre nacionalistas y cosmopolitas. De esta forma, mi crítica a la posición de Miller es interna: no cuestiono su punto de partida sino que, por el contrario, lo concedo. La tesis que defiendo es que esas consideraciones no tienen las consecuencias anti-cosmopolitas señaladas por Miller. En lo que sigue argumento por qué ello es así.

\section{Psicología moral y justicia distributiva}

Miller asegura que el cosmopolitismo está fundado sobre una concepción equivocada de psicología moral. En particular, Miller arguye que el «universalismo ético» - la concepción de la agencialidad moral que, según él, es típicamente adoptada por aquellos que suscriben una posición cosmopolita - es errada por dos razones. Por un lado, a su juicio, la forma en que los cosmopolitas entienden el nexo entre identidad personal y agencialidad moral es equivocada. Asimismo, él afirma que los cosmopolitas adoptan una concepción dudosa de la relación entre la agencialidad y la motivación morales.

sería una teoría de la justicia propia para la humanidad». Tan, «The demands...», cit., p. 164. De todos modos, ello no significa que el punto no pueda ser cuestionado. Cf. e.g. Weinstock, «National Partiality», pp. 528-533 para una posición crítica al respecto. Por mi parte, en este trabajo concedo los puntos clave sobre los que los nacionalistas construyen su posición. 
Miller sostiene que los universalistas éticos entienden que el contenido de nuestros deberes morales es conocido por medio de reflexión sobre la naturaleza de la condición humana y sobre qué puede legítimamente demandarse de las personas, independientemente de las conexiones y relaciones locales que tengan. Así las cosas, el contenido de la moralidad sería el resultado de consideraciones puramente racionales. Él asegura que ello constituye un serio error:

[e]l particularista argumentará que tal cosa supone la creación de un hiato entre el deber moral y la identidad personal. Ningún tipo de consideración acerca de quién soy, de dónde vengo o de a qué comunidades pienso que pertenezco son permitidas en mi reflexión moral ${ }^{26}$.

Asimismo, Miller también entiende que la concepción de la motivación moral que es presupuesta por el universalismo ético es dudosa. Así, escribe que, de acuerdo con esta concepción, la única fuente de razones para actuar moralmente proviene de «la convicción racional de que estoy realizando lo que la moralidad me demanda. No puedo ser influenciado por mis sentimientos hacia los objetos de mi deber, así como tampoco tengo permitido guiar mi comportamiento por las reacciones de aquellos que están en rededor mío en mi comunidad» 27 . Sin embargo, Miller arguye que es irrazonable esperar que tal «convicción racional» tenga el peso motivacional requerido, «excepto quizá en el caso de un pequeño número de individuos heroicos que están genuinamente capacitados para gobernar sus vidas por puras consideraciones de principio» ${ }^{28}$. El caso es que la vida moral de los seres humanos comunes, contrariamente a la de estos casos especiales, requiere de sentimientos de todo tipo hacia amigos, familiares, colegas, etc. Miller dice que «la razón imparcial dicta que yo debo realizar tales y cuales acciones. Pero, ¿por qué ello me da a mí una razón para realizar ello?» ${ }^{29}$. La pregunta por supuesto es retórica. Miller entiende que los seres humanos «deben contar con un conjunto complejo de motivos para cumplir con los requerimientos de la moralidad -motivos tales como el amor, el orgullo, la vergüenza, así como también de convicciones racionales» ${ }^{30}$.

26 Miller, On Nationality, cit., p. 57. En cambio, los nacionalistas enfatizan el rol de la pertenencia a una determinada comunidad política. Por ejemplo, Tamir asegura que «la pertenencia a una nación es un factor constitutivo de la identidad personal». Tamir, op. cit., p. 72. Tan explica que «los nacionalistas liberales entienden que la pertenencia a una cultura nacional constituye un bien liberal importante porque la cultura [nacional] provee a los individuos del contexto de elección en el cual ellos pueden formar, perseguir y revisas sus concepciones del bien. El valor moral de los individuos constituye el aspecto crucial aquí, en vez del valor de la nación [considerado de forma] independiente de lo que los individuos valoran [de hecho]». Tan, Justice without..., cit., p. 99.

27 Miller, On Nationality, cit., p. 57.

${ }_{28}$ Ibid., p. 58.

29 Miller, «The Ethical Significance...», cit., p. 651.

30 Miller, On Nationality, cit., p. 58. 
La tesis de la parcialidad para con los compatriotas encuentra su lugar en este momento. Como señalé en la sección 3, un sentimiento importante que muchos ciudadanos desarrollan tiene precisamente un carácter nacionalista. Efectivamente, los vínculos que las personas tienen para con los miembros de sus propias comunidades políticas tienen una profunda relevancia moral para muchos individuos. Por su parte, Miller considera que la única forma de ponderarlos adecuadamente es bajo una concepción particularista ética; a su juicio, estos sentimientos no pueden ser acomodados en un marco universalista ${ }^{31}$. En este sentido, Miller asegura que el cosmopolitismo constituye «una forma naif de internacionalismo que está fundamentado en una visión inadecuada de la ética y que parece ofrecer una solución simple al problema de las obligaciones internacionales pero al costo de perder contacto con la forma en que en realidad pensamos sobre tales temas» ${ }^{32}$. El punto de Miller es que la concepción de la motivación moral más defendible es incompatible con las demandas morales del cosmopolitismo. Los individuos ponderan especialmente sus relaciones para con los miembros de su comunidad política y ello implica una consideración especial de sus intereses, consideración que ellos no tienen para con el resto de los habitantes del globo. La otra cara de esta moneda es que los individuos no están moralmente motivados para cumplir con las demandas de una concepción cosmopolita de la justicia internacional.

De este modo, la concepción de la motivación moral más defendible —el particularismo moral - sería incompatible con las demandas morales del cosmopolitismo. Miller entiende que el reconocimiento de lealtades y deberes especiales puede ser únicamente acomodado en una concepción particularista de la agencialidad moral y él asegura que esta concepción es incompatible con el cosmopolitismo. Los ciudadanos de las diferentes naciones valoran y ponderan especialmente sus relaciones para con sus compatriotas y entienden que ello conlleva una consideración especial de sus intereses. Por tanto, Miller cree que las personas están normalmente motivadas para satisfacer las demandas de sus conciudadanos, como típicamente lo están para hacer lo propio respecto de sus amigos o familiares. Sin embargo, ellos normalmente no tienen tal consideración para con los miembros de otras comunidades políticas. Consiguientemente, las personas no estarían normalmente motivadas para cumplir con las demandas de una concepción cosmopolita de la justicia internacional. Dicho de otra forma: dadas las características normales de las personas, el cosmopolitismo sería una concepción moral demasiado exigente. El cosmopolitismo sería una concepción moral para unos pocos «héroes» que se ven movidos a la acción únicamente por consideraciones racionales pero no para personas regulares.

\footnotetext{
31 Cf. ibid., pp. 59-64.

32 Miller, «The Ethical Significance...», cit., p. 648.
} 
El ataque de Miller al cosmopolitismo se basa en el enorme esfuerzo que normalmente las personas deberían realizar para satisfacer las demandas que imponen principios de justicia de alcance global. La vida moral de las personas tiene profundos sentimientos parcialistas y esos sentimientos son necesariamente limitados en alcance. Por tanto, para cumplir con las demandas de la concepción cosmopolita, los individuos deberían verse movidos a actuar moralmente por consideraciones puramente racionales o de principio. Creer que ello podría ser el caso es un error en tanto esa no es la forma que, a los ojos de Miller, tiene la acción moral. En cambio, Miller asegura que una concepción razonable de la moralidad debe adoptar un enfoque «humenano» que «antes que desestimar las creencias y sentimientos ordinarios a menos que pueda mostrarse que tienen un fundamento racional, los deja en su lugar a menos que se produzcan argumentos de peso para desestimarlos» ${ }^{33}$. Así, en la concepción humeana de Miller, los sentimientos y lealtades de las personas constituyen «datos morales». El punto crítico es que las concepciones universalistas estarían profundamente reñidas con estos elementos ${ }^{34}$. Miller asegura que

[n]o puede tratarse de dar razones racionalmente convincentes para que las personas tengan apegos nacionales. Lo que podemos hacer es comenzar por la premisa de que las personas generalmente tienen tales apegos y lealtades y a continuación tratar de construir una filosofía política que los incorpore ${ }^{35}$.

La concepción de la justicia internacional que podemos construir sobre esa base no puede ser una forma de cosmopolitismo. Muy por el contrario: el rol fundamental que la identidad nacional juega en la vida de las personas da lugar a una concepción anti-cosmopolita, que involucra sentimientos de parcialidad para con los compatriotas. Miller dice que «porque me identifico con mi familia, mi facultad o mi comunidad local, yo reconozco que tengo obligaciones para con los miembros de estos grupos que son diferentes de las obligaciones que tengo para con la gente en general» ${ }^{36}$.

El énfasis que Miller pone en la «racionalidad» del cosmopolitismo involucra un juicio acerca de la incapacidad de esta concepción de la justicia distributiva para generar los sentimientos necesarios que las personas necesitan para cumplir con sus obligaciones. Según Miller, la ciudadanía tiene un basa-

33 D. Miller, «In Defense of Nationality», en Citizenship..., cit., p. 25. Michael Freeman asegura que los cosmopolitas pueden acomodar este punto sin mayores dificultades. Cf. M. Freeman, «Nation-State and Cosmopolis: A Response to David Miller», Journal of Applied Philosophy, Vol. 11, No. 1 (1994), pp. 82-83.

${ }^{34}$ La expresión «datos morales», así como la idea de que las teorías universalistas están profundamente reñidas con ellos, es de D. Weinstock, «Miller on Distributive Justice», en D. Bell y A. de Shalit (eds.), Forms of Justice: Critical Perspectives on David Miller's Political Philosophy, Lanham, Rowman \& Littlefield, 2003, p. 270.

35 Miller, «In Defense...», cit., p. 25.

36 Miller, On Nationality, cit., p. 65. 
mento nacional y sólo puede tener un fundamento en ese nivel ${ }^{37}$. El poder motivacional de la moralidad es efectivo sólo cuando está integrado con un fuerte sentimiento de identidad y pertenencia. Y ese sentimiento no se da a nivel global. De esta forma, el fundamento de la posición anti-cosmopolita de Miller es doble ${ }^{38}$. Miller cree que las obligaciones morales sólo pueden tener lugar entre individuos que mantienen ciertos lazos afectivos ente sí y, a su juicio, las personas típicamente se identifican con sus compatriotas antes que con los miembros de otras comunidades. Así, Miller afirma que principios de moralidad política no pueden ser aplicados en un ámbito que traspase las fronteras nacionales debido a que en ese nivel los principios harían demandas excesivas y por tanto las personas serían incapaces de actuar del modo requerido. De este modo, Miller argumenta que el cosmopolitismo es una concepción de la justicia distributiva carente de fundamentos.

\section{4. ¿Razones para la parcialidad nacional?}

Considero que las consideraciones caracterizadas en la sección 3 no logran motivar el rechazo de la concepción cosmopolita en materia de justicia distributiva internacional. A mi juicio, en primer lugar, no es del todo claro por qué Miller piensa que las personas no podrían estar movidas a actuar de acuerdo a principios de justicia cosmopolita por razones morales descubiertas tras reflexión acerca de la condición humana y de lo que legítimamente puede pedírsele que hagan. Miller no presenta elementos de juicio concluyentes a favor de su posición al decir que sólo unos pocos «héroes» estarían motivados a hacerlo. Dicho de otro modo: Miller no presenta razones de peso para trazar la línea entre lo que sí puede considerarse un requerimiento legítimo y lo que no puede ser así considerado en el lugar en que lo hace simplemente señalando que algunas personas encontrarían muy costoso cumplir con principios de justicia de alcance internacional. Ello también podría ocurrir en el interior de las fronteras nacionales $y$, por tanto, esa consideración no es suficiente para motivar el rechazo de la concepción cosmopolita. Los límites de las diferentes comunidades políticas nacionales no son especialmente relevantes para trazar una línea demarcatoria entre espacios especialmente aptos para la justicia distributiva y contextos en los que esta noción no puede tener lugar.

La afirmación recién realizada cobra un cariz especialmente dramático cuando consideramos la forma en que el propio Miller entiende a los requerimientos que legítimamente pueden hacérseles a las personas en contextos estatales. Miller cree que las demandas morales pueden ser muy exigentes den-

37 Miller es explícitamente escéptico acerca de la posibilidad de desarrollar una forma de ciudadanía cosmopolita en «Bounded Citizenship», en Citizenship..., cit., pp. 81-96.

38 Cf. S. Caney, Justice Beyond Borders: A Global Political Theory, Nueva York, Oxford University Press, 2005, p. 131. 
tro de las fronteras nacionales. Por ejemplo, Miller considera que la noción de ciudadanía debe ser entendida en términos «republicanos», lo que involucra una dedicación activa a la promoción del bien común y un fuerte deseo de participar en la política democrática ${ }^{39}$.

A los efectos de mi argumento, no es necesario focalizar el análisis en la racionalidad de la noción de «ciudadanía ligada» que desarrolla Miller para dar cuenta de su modelo republicano de ciudadanía. En cambio, me alcanza con señalar que se trata de una noción ciertamente demandante y, quizá, si nos ceñimos a lo que él enfatiza cuando critica a la concepción cosmopolita, excesivamente demandante. Ahora bien, independientemente de sus méritos intrínsecos, no parece excesivo afirmar que esta noción no está empíricamente confirmada por la forma en que los ciudadanos se comportan habitualmente para con sus compatriotas en las diferentes comunidades políticas nacionales. Sin embargo, ello no parece hacer que Miller la considere irrazonable. Aun cuando las personas no se vean típicamente motivadas a actuar sobre esa base, ello es irrelevante para considerar el carácter legítimo o justificado de esas consideraciones. Así las cosas, ¿por qué las demandas de la justicia cosmopolita sí son inadecuadas y las de la ciudadanía republicana no lo son, cuando ambas concepciones normativas demandan del mismo modo más de lo que pareciera que los ciudadanos regulares hacen habitualmente? El caso es que Miller no ofrece razones suficientes para trazar la línea moral justo sobre la línea que divide a las diferentes naciones. El señalamiento de que la justicia cosmopolita es demandante también se aplica a la ciudadanía republicana. Por tanto, ese elemento, por sí mismo, no constituye una consideración suficiente para adoptar una concepción nacionalista en materia de justicia distributiva internacional.

Quizá sea útil realizar una aclaración. Miller sostiene que en caso de que las naciones estén organizadas políticamente como Estados, las personas tendrían derechos y obligaciones en tanto que ciudadanos además de sus obligaciones como miembros de una nación ${ }^{40}$. Por supuesto, la pertenencia a una misma organización política estructurada institucionalmente como Estado puede tener efectos poderosos sobre la forma en que las personas visualizan sus vínculos y relaciones con sus conciudadanos. En cualquier caso, las personas tendrían obligaciones específicas —obligaciones de ciudadanía- en virtud de compartir el mismo esquema institucional. Por tanto, en este caso,

39 Miller escribe que «[1]a ciudadanía involucra [...] el deseo de tomar medidas concretas para defender los derechos de los demás miembros de la comunidad política y, más generalmente, de promover los intereses comunes. El ciudadano es aquel que va en ayuda de un conciudadano que se cae en la calle y uno que interviene cuando le es posible para prevenir que se cometa un crimen». Miller, «Bounded...», p. 83. Miller también sostiene que «el ciudadano republicano juega un rol activo en el control formal e informal de los excesos del gobierno [...] como una forma de expresar su compromiso con la comunidad». Ibíd., pp. 83-84.

40 Cf. Miller, On Nationality, cit., pp. 70-73. 
las obligaciones de las personas para con los restantes miembros de su comunidad política sí estarían delimitadas por las fronteras políticas del Estado-nación.

Sin embargo, estas consideraciones no son suficientes para resolver la cuestión entre nacionalistas y cosmopolitas. En este caso, la justificación de la línea que divide al conjunto de aquellos a los que las personas estarían obligados (los compatriotas) de aquellos que a los que no (los extranjeros) se basa en la existencia de lazos político-institucionales antes que nacionales. Por tanto, la dificultad mencionada no se ve resuelta señalando que las personas mantendrían ciertas relaciones de un tipo especial que generan deberes para con sus compatriotas (aquellas vinculadas a la noción de ciudadanía) en caso de que las naciones conformen Estados. Miller debe resolver la cuestión apelando únicamente a elementos relacionados con la pertenencia a la misma comunidad nacional, independientemente de si ella se organiza políticamente como Estado soberano o no. Los efectos motivacionales que pueda tener la organización política de la comunidad como Estado no son relevantes al momento de considerar las obligaciones que, a juicio del propio Miller, las personas tienen en virtud de pertenecer a una nación determinada. Así, en este sentido, la posición de Miller es mucho más débil que la de otros autores anti-cosmopolitas que fundamentan su rechazo a la idea misma de justicia global sobre la base de la inexistencia de un Estado mundial. Por ejemplo, ésta es la posición adoptada por Thomas Nagel. Nagel asegura la importancia del Estado es de tal magnitud que sin él no podemos «ni siquiera formar una idea inteligible de la justicia global» ${ }^{41}$. Así, Nagel considera que la idea misma de justicia está intrínsecamente ligada a la existencia del Estado y, consiguientemente, entiende que la inexistencia de un Estado mundial implica la inexistencia de principios de justicia distributiva de alcance global.

La consideración del carácter demandante de la noción de ciudadanía no es el único problema que enfrenta la posición milleriana. No parece excesivo afirmar que muchos ciudadanos en el interior de sus propias comunidades políticas podrían argüir que la ciudadanía republicana no toma en cuenta su propia parcialidad hacia sus amigos o familiares frente al resto de sus conciudadanos, de manera análoga a la forma en que la justicia cosmopolita no toma en consideración la parcialidad para con los compatriotas. Esta indicación brinda elementos de juicio adicionales para cuestionar la tesis de que el cosmopolitismo sería irrazonable porque personas regulares no estarían motivadas a cumplir con principios de justicia de alcance global. El problema radica en que típicamente no pensamos que nuestra disposición para satisfacer las demandas de aquellos que son «cercanos y queridos» sea relevante a la hora de determinar la existen-

41 T. Nagel, «The Problem of Global Justice», Philosophy \& Public Affairs, Vol. 33, No. 2 (2005), p. 114. La presentación y evaluación detallada de la posición de Nagel están por fuera del alcance del presente trabajo. 
cia y contenido de principios de justicia de alcance nacional. En cambio, nosotros consideramos que la existencia de esos lazos no debería ser un escollo en la caracterización de los principios de justicia distributiva que tienen un alcance más amplio que nuestro círculo familiar o de amistades.

Ahora bien, si ello es así cuando focalizamos nuestra atención en este contexto particular, ¿por qué esta consideración se vuelve especialmente relevante en la discusión sobre justicia global? El punto en cuestión es similar: seguramente estamos más motivados para satisfacer las demandas de aquellos que son más próximos a nosotros en uno y otro contexto. Sin embargo, la evaluación que Miller hace de ello es radicalmente diferente en uno y otro ámbito. Mientras que cuando consideramos la existencia y el contenido de nuestros deberes morales para con los restantes miembros de nuestra comunidad política los vínculos afectivos que tenemos para con nuestros amigos y familiares no son considerados un escollo. En cambio, la existencia de lazos emocionales (por cierto, más débiles) para con nuestros compatriotas sí se transforma en un elemento de un peso fenomenal al momento de considerar la existencia de principios de justicia de alcance global. Ahora bien, el elemento relevante en ambos casos parece análogo: típicamente nos mostramos mucho más dispuestos para cumplir con las exigencias de la moralidad cuando las personas que están en juego son cercanas a nosotros, sean ellas amigos y familiares o compatriotas. En realidad, la consideración del punto en cuestión pareciera mostrar que la evaluación de las demandas morales no debería fundarse meramente en aquello que los individuos regulares se ven típicamente motivados a realizar. ¿Por qué hacer a la justicia rehén de nuestra disposición a actuar de una u otra forma?

Entiendo que una posible réplica a mi argumentación podría ser la siguiente ${ }^{42}$. Existe una profunda diferencia entre las dificultades que constituye la parcialidad que típicamente generan los lazos afectivos que tenemos para con nuestros amigos y familiares respecto de la motivación para cumplir con principios de justicia internos y el problema que genera la parcialidad que tenemos para con nuestros compatriotas respecto del cumplimiento de principios de justicia globales. En el primer caso, el obstáculo que generan los lazos emocionales que tenemos para con nuestros amigos y familiares puede ser superado porque también tenemos lazos afectivos con nuestros compatriotas. Sin embargo, la inexistencia de lazos de esa índole a nivel global haría que no podamos superar las trabas respecto de la motivación que imponen los vínculos que tenemos en nuestras comunidades nacionales. La justicia cosmopolita tiene un carácter excesivamente demandante porque no puede apoyarse en los lazos afectivos que tenemos, mientras que una concepción igualitaria de la justicia doméstica sí puede apelar a otros lazos emocionales además de los que tenemos con nuestros familiares o amigos.

${ }^{42}$ El punto me fue sugerido por Uwe Steinhoff. 
Por mi parte, creo que esta objeción es profunda y, seguramente, sería compartida por los nacionalistas. Así y todo, no estoy convencido de su genuino carácter destructivo. ¿Es cierto que las personas están motivadas a cumplir con principios de justicia nacionales en vez de con las demandas que hacen aquellos que les son «cercanos y queridos» porque, aunque tienen profundos lazos afectivos con estos últimos, también se identifican con aquellos que forman parte de su misma comunidad nacional? Creo que no. La existencia de lazos afectivos puede ser ciertamente importante para mover a los individuos a cumplir con sus obligaciones morales. Pero no son el único elemento relevante. En el caso en consideración, creo que podemos afirmar que muchas veces actuamos como debemos a pesar de los vínculos que tenemos para con nuestros familiares o amigos sin tomar en consideración los vínculos que también tenemos con nuestros compatriotas. Así, no deberíamos cargar demasiado las tintas en el tipo de vínculo que tenemos para con nuestros compatriotas puesto que el caso es que ese elemento muchas veces no es relevante para dar cuenta de nuestra forma de comportarnos. Por consiguiente, estimo que la analogía trazada más arriba se mantiene en pié.

Las dificultades que enfrenta la posición de Miller no se limitan a las consideradas hasta el momento; existen otras más profundas. Como vengo señalando, Miller considera que el cosmopolitismo requiere demasiado de las personas y, por tanto, que es una concepción moral para «héroes» especialmente motivados antes que para personas regulares. Ahora bien, por mi parte, estimo que esta calificación no ofrece mayores razones para considerar errada a esta posición moral. En realidad, pareciera que es la posición internalista de Miller la que se ve dañada cuando utilizamos este vocabulario para argumentar en materia de justicia. Estimo que está fuera de discusión que muchas de nuestras sociedades domésticas (seguramente algunas más que otras) son injustas. Ahora bien, esta situación, si bien le concierne a algunas personas, también no parece afectar mayormente a otras. Cuando consideramos el caso de aquellos que no se ven motivados a reparar las injusticias que caracterizan a sus propias comunidades políticas, el caso pareciera ser que las demandas morales son tan abstractas a sus ojos como, según Miller, lo son las demandas de la justicia cosmopolita en el ámbito internacional. Así las cosas, si el argumento milleriano es tan potente como él cree, pareciera que sus consecuencias son más amplias que las que considera el propio Miller, puesto que ellas atentarían contra la racionalidad de cualquier concepción de la justicia doméstica medianamente demandante. Sin embargo, muchos no diríamos que ello es el caso (al menos por esa sola razón). Las prescripciones de la moralidad de sentido común también son demandantes ${ }^{43}$. Pero ello no hace que las

43 Con esto no quiero afirmar que el sentido común moral afirma que estamos obligados a volver justas a nuestras sociedades (que son injustas). Ciertamente, muchas personas consideran que tienen el deber de no cometer injusticias, pero que no tienen el deber de remover las injusticias presentes. Ahora bien, si esto es así, ¿podemos mantener que el deber de no cometer 
abandonemos o las consideremos injustificadas. Muy por el contrario: continuamente utilizamos un fuerte lenguaje normativo para criticar a aquellos (incluyendo a nosotros mismos) que no cumplen con sus obligaciones morales y usualmente no consideramos que ello implique ser demandantes en demasía. Pero el caso es que si lo que dice Miller es cierto nuestra práctica común de crítica moral estaría injustificada. Por supuesto, típicamente no consideramos que ello sea el caso. Así, parece legítimo sostener que la relevancia de estas consideraciones en el caso de la justicia internacional es limitada.

Las dificultades que vengo señalando son particularmente relevantes respecto de la concepción normativa particular favorecida por Miller. El caso es que Miller mismo reconoce que el hecho de que típicamente nos preocupemos especialmente por los intereses de aquellos «cercanos y queridos» constituye un serio problema ${ }^{44}$. La dificultad es particularmente grave para Miller, dado el punto de partida humeano de su posición. Como él mismo señala, este hecho impacta y, a su juicio, de hecho, distorsiona el peso de nuestras obligaciones qua ciudadanos pertenecientes a una comunidad política particular. Miller escribe que

[e]stamos mayormente preocupados por nuestra familia y por otras relaciones que mantenemos en nuestra comunidad; a continuación [estamos interesados] en nuestra propia inmersión en relaciones económicas e instrumentales [en general]; y, finalmente, [prestamos atención] a nuestra ciudadanía que es, para la mayor parte de las personas, un modo de asociación remoto y pobremente entendido. [Así,] [d]ebido a dificultades conceptuales, estamos propensos a dar demasiado peso a las demandas de justicia que provienen de nuestras comunidades inmediatas y muy poco peso a las demandas asociadas a la ciudadanía ${ }^{45}$.

Estas dificultades parecen desestabilizar a la propia posición crítica milleriana respecto de las concepciones de la justicia internacional de corte cosmopolita. Él acepta que las personas tienen obligaciones que no logran comprender ni que mucho menos cumplen. Sin embargo, ello no lo lleva a concluir que tales obligaciones no existan o que sean injustificadas ${ }^{46}$. Por tanto, pare-

injusticias (que es el que es relevante en este contexto) es realmente demandante? Ciertamente, una respuesta completa a esta cuestión sólo tiene sentido una vez que hemos especificado cuál es el contenido de la moralidad de sentido común que estamos considerando. Así y todo, creo que podemos mantener que, muchas veces, cumplir con (algunas de) nuestras obligaciones de sentido común puede ser bastante exigente, por ejemplo si la moralidad de sentido común incluye deberes positivos.

44 De hecho, quizá se pueda argumentar que los vínculos de nacionalidad son demasiado lábiles como para motivar el cumplimiento de demandas morales. Cf. B. Parekh, «The Incoherence of Nationalism», en R. Beiner (ed.), Theorizing Nationalism, Albany, State University of New York Press, 1999, esp. pp. 314-316.

45 D. Miller, Principles of Social Justice, Cambridge, Harvard University Press, 1999, p. 40.

46 En realidad, la verdadera dificultad radica en entender cómo la concepción de psicología moral de la que parte Miller es compatible con su concepción de la ciudadanía, debido a la 
ce legítimo cuestionar que el internalismo de Miller sea tan dañino cuando focalizamos nuestra atención en las demandas de la justicia cosmopolita pero que no lo sea cuando consideramos las obligaciones de los ciudadanos para con los restantes miembros de sus comunidades políticas. Por mi parte, creo que Miller es sencillamente incapaz de ofrecer una respuesta adecuada a este problema. En cambio, desde una perspectiva cosmopolita, este fenómeno es irrelevante en tanto es este hecho - la existencia de obligaciones especiales para con los compatriotas - el que requiere de una justificación adicional ${ }^{47}$.

Finalmente, quisiera detenerme en una dificultad adicional que enfrenta la posición de Miller. El punto crítico es el siguiente. Si bien Miller no cree que existan deberes de justicia a nivel global, él de todos modos reconoce que existen obligaciones morales que traspasan las fronteras de las comunidades nacionales. A su juicio, ellos fundan una forma «débil» de cosmopolitismo:

[...] el cosmopolitismo débil [...] entiende que la moralidad es cosmopolita sólo en parte: existen algunos principios válidos de igual consideración de alcance universal, aunque también existan principios independientes con un alcance más restringido. De acuerdo al cosmopolitismo débil, por tanto, podemos deber realizar cierto tipo de tratamiento a todos los seres humanos independientemente de cualquier relación que tengamos con ellos, mientras que existe otro tipo de tratamiento que debemos tener para con aquellos con quienes nos relacionamos en ciertas formas y ningún tipo de obligación se deriva del otro ${ }^{48}$.

Miller sostiene que el fundamento del cosmopolitismo débil es la protección de los intereses vitales de las personas, pero que «debido a que tal protección no constituye la totalidad de nuestra consideración para con los demás, podemos combinar un cosmopolitismo [débil] de un compromiso con la prioridad de los intereses vitales con principios más localizados para gobernar la distribuciones de los recursos y beneficios no-esenciales» ${ }^{49}$.

forma demandante en que la entiende. Por ejemplo, Miller considera que uno debe «cumplir las tareas-políticas y sub-políticas-que la ciudadanía involucra» aun cuando ellas sean costosas y puedan «no ser experimentadas como placenteras». Miller, «Bounded...», cit., pp. 84-85. Así las cosas, considero que es legítimo preguntarse si esta concepción de la ciudadanía es realmente compatible con un internalismo estricto. En todo caso, en caso de que lo fuera, entonces no ofrecería razones para no considerar que también lo sería con el cosmopolismo.

47 En este sentido, Pablo Gilabert señala que, desde la perspectiva cosmopolita, «las reflexiones de la justicia deben comenzar con principios globales y sólo luego pueden dirigirse a contextos específicos. Esto no quiere decir que [un cosmopolita como] Pogge niegue la existencia de responsabilidades de justicia que son estatales y no globales. Lo que significa es, más bien, que la parcialidad a favor de los «queridos y cercanos» requiere siempre de una justificación, y que esta justificación debe apelar a principios que pudieran ser razonablemente aceptados por todas las personas, incluyendo aquellos que residen más allá de cualquier contexto nacional». Gilabert, op. cit., p. 207.

48 D. Miller, «The Limits of Cosmopolitan Justice», en D. Mapel y T. Nardin (eds.), International Society, Princeton, Princeton University Press, 1998, pp. 166-167.

49 Ibid., p. 167. 
La distinción milleriana entre cosmopolitismo débil y fuerte es sólo una forma de distinguir entre deberes de humanidad y genuinos deberes de justicia. Ahora bien, más allá de la razonabilidad de la posición de Miller en este respecto, creo que podríamos seguir con la línea argumental desarrollada más arriba señalando que parece difícil que las personas universalmente se vean normalmente motivadas para cumplir con principios de moralidad humanitaria ${ }^{50}$. Así, pareciera que, cuando es tomado a pie juntillas (como Miller hace para atacar al cosmopolitismo en su versión fuerte), el poder destructivo de las consideraciones psicológico-morales que adopta es mucho más destructivo de lo que el propio Miller considera. Sin embargo, difícilmente podría argumentarse que la razonabilidad de una concepción de moralidad humanitaria que involucra el respecto por los derechos básicos de las personas, la prohibición de «explotar a aquellos que son vulnerables de nuestras acciones» $\mathrm{y}$ «la obligación de asegurar que todas las comunidades políticas tengan la oportunidad de determinar su propio futuro y de practicar la justicia entre sus miembros», lo que implica «una base adecuada de recursos» y un «entorno económico tolerable» ${ }^{51}$ se vería puesta en dificultades porque seguramente las personas no se mostrarían típicamente motivadas a cumplir con sus prescripciones. Quizá sólo unos pocos «héroes» sean capaces de satisfacer las demandas morales que imponen los principios de moralidad humanitaria millerianos y que, consiguientemente, algunos puedan señalar que esa concepción es muy exigente cuando se considera la forma en que se comportan personas regulares. Pero ello parece no hacer mella en nuestra consideración de tales deberes morales. Así, de la misma forma, el caso parece ser que el hecho de que muchas personas no se verían motivadas a cumplir con principios de justicia globales no ofrece mayores razones para abandonar la posición cosmopolita.

Sin lugar a dudas, la moralidad cosmopolita es demandante y su cumplimiento requeriría de un esfuerzo considerable por parte de las personas. Pero ese parece un rasgo característico de la moralidad y, del mismo modo que parece razonable exigir que las personas cumplan con principios de justicia nacionales y principios humanitarios de alcance internacional, también parece razonable exigir que las personas cumplan con principios de justicia globales. Por tanto, sostener que los principios de moralidad política cosmopolitas son demandantes no constituye una razón suficiente para rechazarlos. En reali-

50 Quizá sea en virtud de esta dificultad que Rawls reconozca la necesidad de una cierta afinidad entre las personas para cumplir con los principios humanitarios que, a su juicio, existen entre los pueblos. Igualmente, de todas formas, él parece entender que no debemos guiarnos por la posible falta de afinidad que existe actualmente entre las personas en diferentes partes del planeta. Cf. J. Rawls, The Law of Peoples: with «The Idea of Public Reason Revisited», Cambridge, Harvard University Press, pp. 112-113. De cualquier forma, el tratamiento de este punto está por fuera de los objetivos del presente trabajo.

51 Miller, «National Self-Determination...», cit., pp. 174-175. 
dad, si así fuera, quizá deberíamos desembarazarnos de la noción de obligación moral misma. Ese, creo, es un precio demasiado alto, que no estamos dispuestos a pagar.

\section{Conclusión}

En el presente trabajo señalé que la disputa entre nacionalistas y cosmopolitas parece depender del valor que le asignemos a las relaciones asociativas que mantenemos con nuestros compatriotas vis-à-vis el peso relativo que le demos a la idea de misma consideración imparcial hacia los reclamos de las personas en todo el planeta. En tanto parece haber buenas razones para tomar en serio a los dos tipos de consideraciones, cualquier posición que tomemos al respecto puede correr el riesgo de racionalizar nuestras preferencias antes que de adoptar la concepción más razonable. Por mi parte, creo que la concepción nacionalista es errada y que los cosmopolitas están en lo correcto. A mi juicio, es difícil negar que el mundo como una totalidad deba ser regulado por principios de justicia que tengan en consideración los intereses de todas las personas del planeta, al menos si estamos comprometidos con premisas normativas individualistas. Sin embargo, entiendo que es muy probable que un punto de partida de este tipo sea inaceptable para aquellos que adoptan la concepción contraria.

En este trabajo mantuve que las consideraciones psicológico-morales que introduce Miller para favorecer la concepción nacionalista parecen ser un punto de partida adecuado para decidir la cuestión entre esta posición y la cosmopolita. En cualquier caso, Miller recoge un conjunto de ideas que, aún a juicio de aquellos que adoptan la concepción contraria, deberían ser acomodados por cualquier concepción razonable de la justicia distributiva. Sin embargo, sostuve que el argumento psicológico-moral desarrollado por Miller es insuficiente para decidir el debate entre nacionalistas y cosmopolitas. Si lo dicho más arriba es correcto, no es claro que esas ideas permitan fundar la posición que afirma que el alcance de los principios de justicia está circunscripto a las fronteras de los diferentes Estado-nación y que no puede extenderse a un nivel global. Las dificultades de motivación que se presentarían en el caso de la justicia internacional no son típicas de ese ámbito; también están presentes en los ámbitos estatales en los que parece estar fuera de discusión que existen consideraciones de justicia que debemos cumplir.

La conclusión alcanzada parece retrotraernos al punto de partida. Por lo pronto, la disputa entre nacionalistas y cosmopolitas sigue en pie: mis argumentos contra Miller no implican que el cosmopolitismo sea la concepción de la justicia correcta o justificada. El cuestionamiento desarrollado en este trabajo es interno al punto de partida milleriano y, consiguientemente, tiene un alcance limitado. En particular, si bien permite afirmar que la concepción na- 
cionalista no ha demostrado ser una posición normativa superior, no permite reivindicar totalmente al cosmopolitismo. De todos modos, no creo que la conclusión obtenida sea menor. Las consideraciones psicológico-morales que Miller enfatiza son en general consideradas cruciales para decidir la cuestión de si una concepción normativa es o no atendible. En este sentido, muchos creen que el señalamiento de que el utilitarismo es una concepción de la justicia excesivamente demandante muestra el carácter injustificado de esta concepción. Por tanto, mostrar que el cosmopolitismo en todo caso tiene las mismas dificultades que cualquier concepción igualitaria de alcance doméstico constituye un avance teórico considerable. En algún sentido, permite considerar que la idea misma de fundamentar una concepción de la justicia no es sólo una forma de racionalizar nuestras ideas morales preteóricas, sino también de mostrar que la moralidad en general y la moralidad política en particular tienen un carácter crítico, que nos debería llevar a replantear el modo en que organizamos nuestras sociedades domésticas así como las relaciones internacionales. De otra forma, la filosofía política se transforma en poco más que en una celebración del statu quo. 